\title{
AC 2012-3348: JUST-IN-TIME TEACHING: COMPUTER SCIENCE MEETS PHYSICS
}

Dr. Alex Pantaleev, State University of New York, Oswego

Alex Pantaleev received a B.A. degree in computer science from the American University in Bulgaria, Blagoevgrad, Bulgaria, in 2003, and M.S. and Ph.D. degrees in computer science from the Ohio State University, Columbus, Ohio in 2007 and 2008, respectively. He is currently an Assistant Professor in the Department of Computer Science at the State University of New York, Oswego.

Dr. Adrian Ieta, State University of New York, Oswego

Adrian Ieta received a B.Sc. degree in physics from the University of Timisoara, Timisoara, Romania, in 1984, a B.E.Sc. degree in electrical engineering from the Politehnica University of Timisoara, Timisoara, in 1992, and a M.E.Sc. degree and a Ph.D. degree in electrical and computer engineering from the University of the Western Ontario, London, Ontario, Canada, in 1999 and 2004, respectively. He was with the Applied Electrostatics Research Centre and the Digital Electronics Research Group, the University of Western Ontario, where he worked on industrial projects and taught. He is currently an Assistant Professor in the Department of Physics, State University of New York at Oswego. Ieta is a member of Professional Engineers of Ontario.

Dr. Carolina C. Ilie, State University of New York, Oswego

(C)American Society for Engineering Education, 2012 


\section{JUST-IN-TIME TEACHING: COMPUTER SCIENCE MEETS PHYSICS}

Increasing student participation inside and outside the classroom is a desirable goal in education. Just-in-Time Teaching (JiTT) is a promising educational methodology that has been shown to work for a wide variety of university courses and audiences, yet it has not been widely adopted in Computer Science. We describe an experiment that compares the use of JiTT in a high-level Computer Science course with its parallel use in two introductory Physics courses. JiTT was originally developed for use in introductory Physics courses, hence our use of such courses as the baseline for our comparison. We assess the method on three courses by applying and analyzing the results of a uniform exit survey distributed to all students involved. We demonstrate positive CS student perceptions of the methodology and similar JiTT-related student responses in the three courses. The method appears effective in increasing student ability and willingness to work independently whether in introductory or advanced courses.

\section{INTRODUCTION}

We describe an experiment that compares the use of the Just-in-Time Teaching (JiTT) [1] methodology in a high level Computer Science course with its use in two introductory Physics courses at a middle-sized Liberal Arts university. We examine student perceptions of this new method across the three courses involved in the experiment. JiTT was originally developed for use in introductory Physics courses, hence our use of such courses as the baseline for comparison. In brief, JiTT is a teaching and learning strategy based on online learning technologies that supplement in-class activities. Its essence is a rapid feedback loop between online student responses, due shortly before class, and an in-class discussion that follows immediately. The instructor adjusts the discussion in order to focus on concepts that the students find particularly difficult, as revealed by their responses to online questions.

The use of JiTT in Computer Science education is not new. However, despite the widespread use of web technologies and interest in active learning in CS education, JiTT has not been widely adopted in this domain. Astrachan [2] described the use of Web-based programming exercises to inform class discussions on algorithmic problem-solving. Bailey and Forbes [3] reported on the use of JiTT in a CS0 course. Carter [4] described an experiment involving JiTT and peer instruction in CS1. Davis [5] noted positive experiences with JiTT in systems and design courses. While the high-level CS course we use in our experiment is a systems course, we also provide extensive results measuring student perceptions of JiTT as well as a comparison with the use of the approach in introductory Physics courses. To our knowledge, no reports on similar cross-disciplinary experiments involving JiTT exist in CS literature.

The high-level course in our experiment is Systems Programming, which provides an introduction to standard operating system calls, the use of $\mathrm{C}$ for systems programming, processes, and other systems concepts. The use of JiTT in this course was compared to JiTT in 
an algebra-based introductory Physics course and in a calculus-based one. For all three courses, we developed online quizzes that students were required to complete. Quiz grades were based on participation as opposed to correctness. The quizzes were due shortly before class, and we used the time between a quiz deadline and the class to read through student responses and adjust the in-class discussion that followed immediately.

During the final week of the semester, we asked students to complete a survey that measured their perceptions of the new approach. The survey questions were uniform across the three courses. We noted a large percentage of positive student responses. We also noted similar JiTTrelated student responses in the three courses, which is encouraging for JiTT use in high-level CS courses, considering that JiTT traditionally performs well in introductory Physics courses.

We aim at comparing the results in the three classes examined and at identifying similarities and differences in JiTT results. We also want to evaluate the appropriateness of using the JiTT for higher-level CSC courses.

\section{JUST-IN-TIME TEACHING}

JiTT is a teaching methodology that relies heavily on the interaction between a web component and a classroom component [1]. Students use the web component outside the classroom as part of their preparation. The aim is to adjust teaching content shortly before class based on students' understanding of and feedback on the concepts learned.

The core of the method consists in the following sequence: students read in advance topics to be taught; they then use the web component, which has been set up by the instructor beforehand, to answer questions on the material they have just read in the form of a short quiz or a series of short problems. The quiz is graded on the basis of participation as opposed to correctness. The instructor reads through students' answers before class, identifying the strengths and weaknesses of the answers and then addresses the weaknesses in class as part of the classroom component of the method.

The JiTT method is highly recommended in various workshops for new faculty, such as the annual workshop of the American Association for Physics Teachers. It was originally designed for introductory Physics courses, and recent results [9] have shown its effectiveness in this domain. This teaching strategy can be used in any field, from Physics to Photography [1, 7, 8], from introductory general education classes to upper level ones, for small or large classes [9]. 


\section{METHODOLOGY}

\subsection{CSC322}

In CSC322 we used the Angel online learning system to support the web component of JiTT. Angel allows the course editor to create surveys in the form of quizzes. It is possible to add questions to a survey in free-form text with basic formatting, which was sufficient for the purposes of the course.

CSC322 class periods were scheduled for Monday, Wednesday, and Friday between 1:50 p.m. and 2:45 p.m. There was approximately one JiTT quiz per week. The days of the quizzes varied depending on factors such as examinations during the week, but their times did not. We would prepare the quiz two days in advance and post it on Angel, and students would have the strict deadline of 1:00 p.m. to answer the quiz and solve the problems in it. That allowed us fifty minutes to read through their solutions and adjust the material we would emphasize in class.

The in-class component of JiTT was served by a discussion immediately following the deadline of each online quiz. Anonymous student answers to each question were shown on the screen. The class first selected the correct answer to the question, and then discussed why it was correct and the potential errors made by the students who submitted incorrect answers. Due to the anonymity of student responses, there was no fear of ridicule, and students were able to gain the necessary knowledge without peer pressure.

An additional opportunity for student feedback in this particular case was the fact that the instructor's office, the classroom used for the course, and the "hang-out" room of the Computer Science student association were all located within the same short hallway. In addition, the time period between 12:25 p.m. and 1:50 p.m. is not used for classes at our university, to allow for lunch time and other activities. This combination of factors allowed students to have lunch in their club room while looking at the quiz problems we had prepared for them and come to the instructor's office to ask clarifying questions, if necessary. We could immediately gauge their level of preparation and understanding based on the questions they asked, and adjust the following classroom discussion accordingly.

The course structure was based on [10], a systems course originating at Carnegie Mellon University. Since JiTT relies heavily on a good textbook, we also used the book provided by the course developers [11]. Our course loosely followed the ICS course structure, as presented in the book.

CSC322 in its modern form is a new course in our department, and this was its first offering in the past decade. To modernize the course we had to alter the material covered, the textbook used, and its relationships to other courses in the department. Hence, we cannot offer a meaningful comparison with previous practices in teaching the course. We do intend to teach CSC322 in a 
more traditional way the next time it is offered in order to assess the performance of JiTT in terms of its impact on student grades and retention.

The following passage is an example question from a JiTT quiz we used in the course. A quiz typically contained three or four questions.

Suppose we are given the task of generating code to multiply integer variable $\mathrm{x}$ by various constant factors $\mathrm{K}$. To be efficient, we want to use only the operations + , -, and $<<$. For the following $\mathrm{K}$, write expressions in $\mathrm{C}$ to perform the multiplication using only the above operations.
A. $\mathrm{K}=17$
B. $K=-7$
C. $K=60$
D. $K=-112$

Participation in JiTT quizzes was worth $10 \%$ of the course grade.

\subsection{PHY111 and PHY112}

The two introductory Physics courses were also structured around JiTT. In PHY111 we used Google Docs to enable the web component of the methodology, while in PHY112 we used Angel in a similar way to CSC322.

Using Google Docs Forms requires a Google account to create the JiTT quizzes. Once the form is created, it can be emailed to the class (student emails are needed). The email contains a link that takes the student to the survey form created, where students input their answers. The instructor can see student answers in a spreadsheet in real time.

The Angel online learning system provides similar functionality. In addition, since it is the online course management system our university uses, students can login with their university-wide usernames and passwords, thus allowing for more security through authentication. InPHY112 we also used Angel to conveniently host other course materials, such as class notes and exam revisions, in one place, accessible by all enrolled students. Our JiTT teaching strategy in this course was accompanied by presentations, board discussions, in-class quizzes, and exams.

\section{ASSESSMENT}

We evaluated the performance of the methodology using an exit survey during the last week of the semester. The questionnaires we used for that purpose in the three courses were identical: 
Q1. On days when there was an online preparation assignment, I was more likely to do the reading assignment?

Q2. After an online preparation assignment, I looked forward to the discussion we would have in class about it.

Q3. I found that the online preparation assignments and the discussions we had in class about them helped me learn the course material better.

Q4. When an answer I submitted was discussed by the class I felt: excited, embarrassed, apprehensive, interested, I don't think my answers were presented to the class.

Q5. In your opinion, which of these options would motivate students to prepare for class by doing the reading assignments? (see appendix for details)

Q6. About how much time per week did you spend outside of class working on this course?

Q7. Please check all that are true about your learning behavior this semester in this course.

Q8. Please provide any other comments or suggestions about the quizzes. The full text of the survey can be found in appendix A.

There were 16 students enrolled in CSC322, of which 13 responded to the survey. PHY111 had 42 students and 20 survey participants, while PHY112 had 46 and 29, respectively.

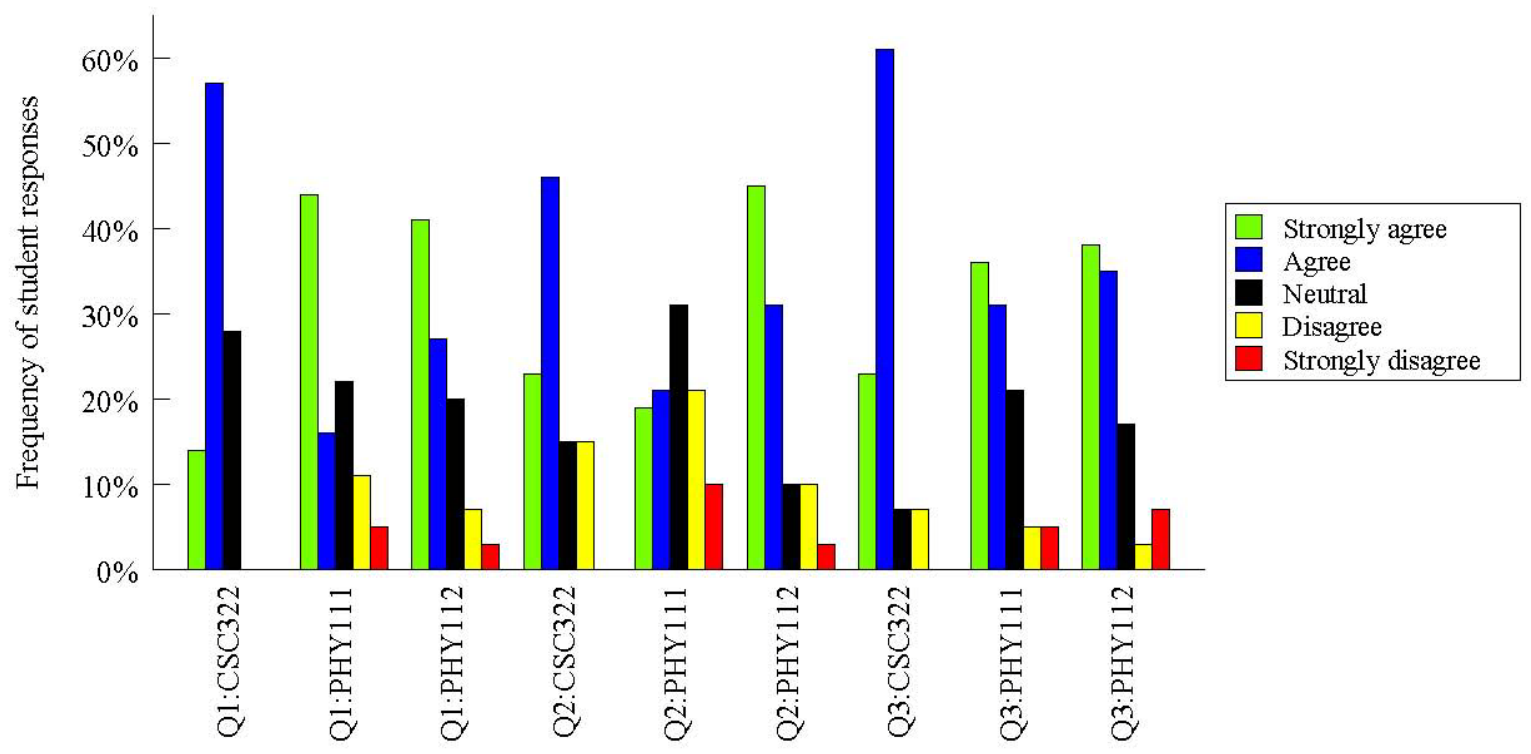

Fig. 1: Student responses to questions 1, 2, and 3. 


\subsection{Analysis}

The first three statements that we asked students to evaluate used a Likert-like scale: Strongly Agree, Agree, Neutral, Disagree, and Strongly Disagree. Figure 1 presents the data we collected.

These statements attempt to assess the perceived effectiveness of the methodology with regard to learning. There is a strong indication that both Computer Science and Physics students believed that the quizzes and discussions helped them manage the material better. It is interesting to note that Physics students have more extreme opinions on their statements: there is a small percentage of Physics students who believe quizzes do not help them at all, while all Computer Science students appreciate the web component at least to an extent. At the other end of the range, Physics students are more enthusiastic about the methodology, while Computer Science students have more moderate positive opinions. One potential factor for this discrepancy might be the relative age of students: while CSC322 is taken primarily by junior and senior students, the majority of PHY111 and PHY112 enrollment consists of first and second-year students. This discrepancy may also stem from the nature of the questions asked: in the two Physics courses the questions were more intuitive, while in CSC322 most answers, especially the last question of each quiz, required deep concentration and mental effort. As a result, a CSC322 quiz likely took far more time to respond to, thus preventing the element of surprise and the feeling of immediate reward.

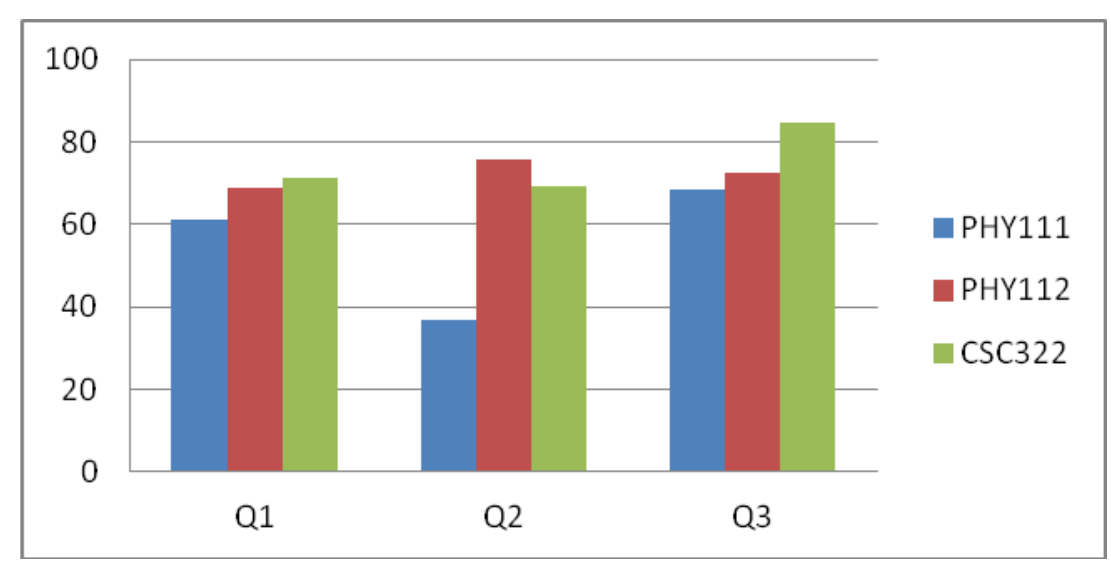

Fig. 2: Agregate ratings for questions 1, 2 and 3.

Fig. 2 shows the aggregate percentage for "strongly agree" and "agree” ratings for questions Q1, Q2 and Q3. It is apparent that the JiTT method had significant impact on the students. They are more likely to do the assignments (Q1), they look forward to the class discussions (Q2), and they perceive they were helped by the online exercises to better learn the course material (Q3). It is also apparent that the greatest help with learning was recorded in the CSC322 course (85\% of the respondents). 
The fourth survey statement evaluates student perceptions regarding in-class discussion of their own answers to web quizzes. Student responses are presented in Fig. 3. The majority of students in both courses responded positively. A large percentage of Physics students (in both Physics courses) did not see their answers discussed, perhaps because of those classes' larger sizes. Again we see Physics students express more emotion in their answers (a larger percentage of them felt excited as compared to Computer Science students), which can potentially be attributed to the age factor discussed previously.

Question five attempts to assess student preferences when comparing the new pedagogy to more traditional and familiar ones. Student responses are presented in Fig. 4. Please note that the total percentages in the three courses exceed 100 due to students electing to choose more than one option. Students in all three classes believe that the web quizzes of JiTT are the optimal way for them to prepare for class. It is interesting to observe that no student in CSC322 and PHY111 elected the "Nothing" option; in our opinion, students have come to appreciate the confidence and preparation that JiTT allows them and would like to have a similar experience with other methodologies, too.

There is a difference in students’ preference for a second-best option: Computer Science students prefer class discussions that assume prior reading, while Physics students opt for daily quizzes instead. One possible reason might be the difference in the level of material in the two courses.

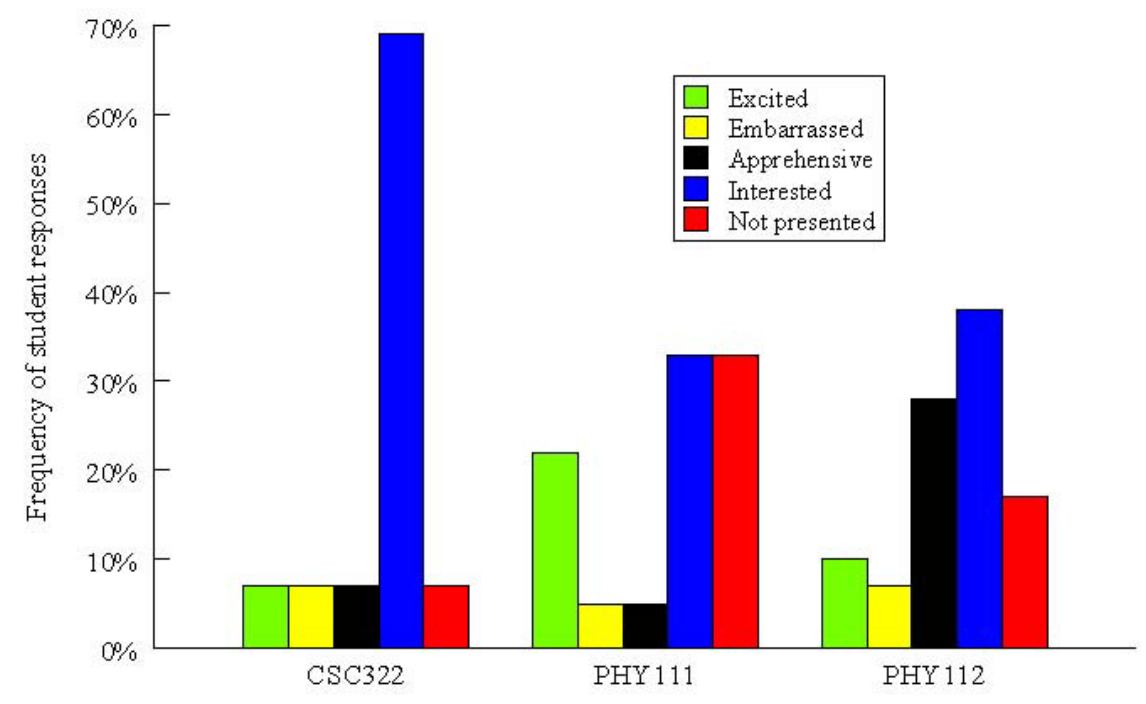

Fig. 3: Student responses to question 4. 


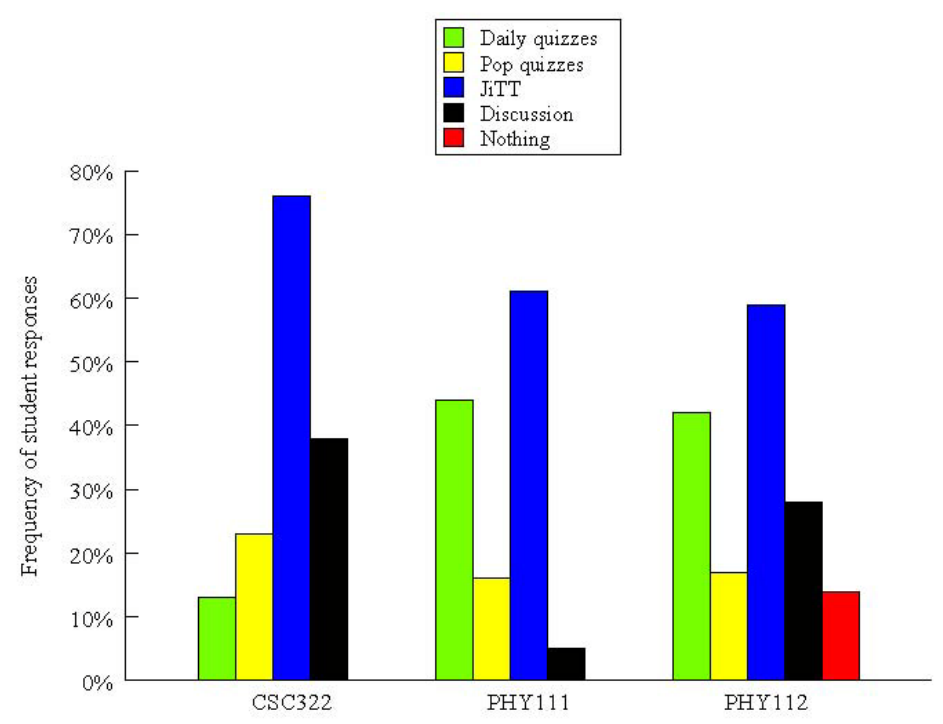

Figure 4: Student responses to question 5.

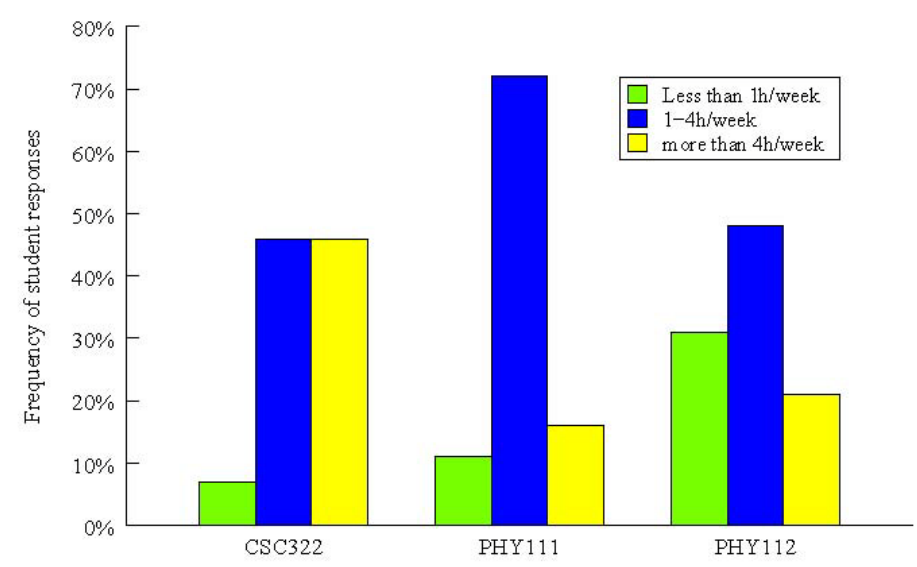

Fig. 5: Student responses to question 6.

\begin{tabular}{|l|c|c|c|}
\hline & CSC322 & PHY111 & PHY112 \\
\hline I almost always read the book before quizzes. & $38 \%$ & $55 \%$ & $48 \%$ \\
\hline $\begin{array}{l}\text { I almost always came to class and was there before class } \\
\text { started. }\end{array}$ & $69 \%$ & $77 \%$ & $55 \%$ \\
\hline I often worked with classmates on the homework. & $30 \%$ & $22 \%$ & $10 \%$ \\
\hline $\begin{array}{l}\text { When I got stuck on a problem, I sought help from the } \\
\text { textbook. }\end{array}$ & $84 \%$ & $77 \%$ & $69 \%$ \\
\hline $\begin{array}{l}\text { When I got stuck on a problem, I visited the professor's } \\
\text { office hours. }\end{array}$ & $7 \%$ & $0 \%$ & $10 \%$ \\
\hline I completed and turned in all of the homework assignments. & $69 \%$ & $94 \%$ & $0 \%$ \\
\hline I participated in all of the online quizzes. & $69 \%$ & $72 \%$ & $17 \%$ \\
\hline I made sure I understood the material before each exam. & $76 \%$ & $83 \%$ & $62 \%$ \\
\hline
\end{tabular}

Table 1 . Student responses to question 7 , 
CSC322 students felt very enriched by the discussions that followed the JiTT online quizzes, as evidenced by some of their freeform responses to the last survey question, while the Physics courses, and PHY112 in particular, had weekly quizzes in addition to the JiTT ones.

Fig. 5 presents student answers to the sixth survey question, which measures the time they spent on the respective course. Computer Science students spent far more time on the course than Physics students, which is indicative of the level of material in CSC322. It is encouraging that in all courses few students spent a trivial amount of time per week to study; thus JiTT has served its primary purpose. Table 1 lists students' responses to the last option-based survey question.

There was no homework in PHY112, which explains student responses to the respective question in the table. One interesting result is the almost complete lack of reliance on professors' office hours by students. We interpret this fact as positive for the JiTT methodology, especially when taken in concert with students' extensive reliance on the textbook.

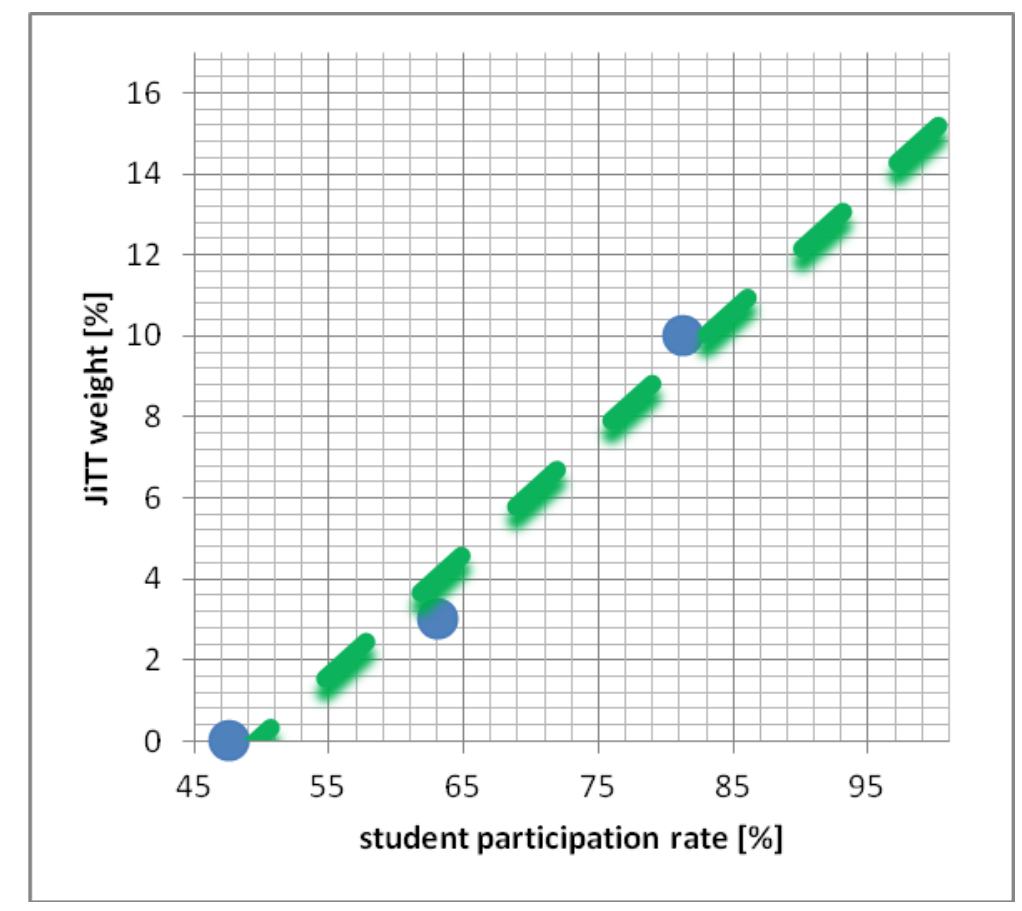

Fig.6: JiTT grade weight versus student participation rate and linear regression line.

Apparently, in all three courses students were satisfied with the class discussions that followed the online quizzes and did not feel the need to seek additional help from the professor.

Quiz participation was voluntary for PHY111 students, while in PHY112 the grade weight was $3 \%$ and CSC322 assigned 10\% extra credit for completing JiTT quizzes. The chart plotting the weight of the JiTT component and student participation rate is given in Fig. 6. The extrapolation of the linear regression line suggests that full class participation to the JiTT component may happen for about $15 \%$ weight assigned to it. On a different JiTT experiment in another Physics 
course (PHY 101), a 10\% weight was used for online quizzes. The participation rate recorded was about $80 \%$, which corresponds well to the chart in Fig. 6 . The present analysis suggests a correlation of student responsiveness with the JiTT grade weight, independent of course topic or level.

\section{Student Comments and Impressions}

We now turn to student responses to the last survey question, which asked for free-form comments. For the purposes of brevity, we present only CSC322 student responses.

"The quizzes were a strong point of the class this semester. It was helpful to see that other people were having a hard time with certain topics as well. I liked the recent structures of the quizzes. There were some concepts to discuss/answer and then a sample program to try coding. They weren't overbearing, and they had a fair amount of information on them.” This student makes the important observation that the quizzes and the following in-class discussions allowed students to be valuable and confident participants in the course, even if they struggled with the material.

"Just throwing this out there but when you are taking 5 classes that all assign reading, and you have a combined 100+ pages to read every single day, plus your work it gets progressively hard to keep up with the reading. The quizzes did help significantly in keeping up with the material.” This student appears to have relied primarily on the quizzes and discussions to deliver the course content. This is an unexpected benefit of JiTT when using dense books with complex material in high-level courses.

\section{CONCLUSIONS}

We have conducted an experiment comparing the performance of the JiTT methodology in a high-level Computer Science course to its performance in traditional JiTT courses. The results from our experiment are encouraging: CS student responses were positive, and their JiTT-related responses were similar to the respective Physics students' responses, which indicate the potential for transferring the technique to Computer Science. The analysis shows that the CSC students felt they were helped the most and the methodology is fit for high-level Computer Science courses. Student comments reinforce such a conclusion. We intend to develop materials necessary to teach other high-level CS courses using this new approach. A calibration of the JiTT grade weight with student participation was attempted and verified later. It appears that independent of course topic or level, there is justification for weights larger than $15 \%$. The method studied appears effective. Nevertheless, increased interaction with students also involves more instructor time for course preparation. According to our experience, we would deem it appropriate to start by developing one course at a time using this method, as two may be too demanding. 


\section{REFERENCES}

[1] G. M. Novak, E. Patterson, A. Gavrin, and C. Wolfgang. Just-in-Time Teaching: Blending Active Learning with Web Technology. Prentice Hall PTR, New Jersey, 1999.

[2] O. Astrachan. Non-competitive programming contest problems as the basis for just-in-time teaching. In FIE '04: Proceedings of the 34th Annual Frontiers in Education Conference, 2004.

[3] T. Bailey and J. Forbes. Just-in-time teaching for cs0. In SIGCSE '05: Proceedings of the 36th SIGCSE technical symposium on Computer science education, pages 366-370, New York, NY, USA, 2005. ACM.

[4] P. Carter. An experiment with online instruction and active learning in an introductory computing course for engineers: Jitt meets cs1. In WCCCE '09: Proceedings of the 14th Western Canadian Conference on Computing Education, pages 103-108, New York, NY, USA, 2009. ACM.

[5] J. Davis. Experiences with just-in-time teaching in systems and design courses. In SIGCSE '09: Proceedings of the 40th ACM technical symposium on Computer science education, pages 71-75, New York, NY, USA, 2009. ACM.

[6] S. P. Formica, J. L. Easley, and M. C. Spraker. Transforming common-sense beliefs into Newtonian thinking through just-in-time teaching. Phys. Rev. ST Phys. Educ. Res., 6(2):020106, Aug 2010.

[7] C. Cookman, S. Mandel, and M. Lyons. The effects of just in time teaching on motivation and engagement in a history of photography course. Scholarship of Teaching and Learning at Indiana University Bloomington, 2007. online presentation.

[8] W.-H. Lin and C.-C. Liu. TIPS: A JiTT and PI pedagogical method with handheld computer as mediating tools. In ICALT '05: Proceedings of the Fifth IEEE International Conference on Advanced Learning Technologies, pages 844-845, Washington, DC, USA, 2005. IEEE Computer Society.

[9] Just-in-time teaching. http://www.jitt.org.

[10] R. E. Bryant and D. R. O’Hallaron. Introducing computer systems from a programmer's perspective. In SIGCSE '01: Proceedings of the thirty-second SIGCSE technical symposium on Computer Science Education, pages 90-94, New York, NY, USA, 2001. ACM.

[11] R. E. Bryant and D. R. O’Hallaron. Computer Systems: A Programmer’s Perspective. Addison-Wesley Publishing Company, USA, 2010. 


\section{APPENDIX}

Exit survey questions

Q1. On days when there was an online preparation assignment, I was more likely to do the reading assignment?

Q2. After an online preparation assignment, I looked forward to the discussion we would have in class about it.

Q3. I found that the online preparation assignments and the discussions we had in class about them helped me learn the course material better.

Q4. When an answer I submitted was discussed by the class I felt: excited, embarrassed, apprehensive, interested, I don't think my answers were presented to the class

Q5. In your opinion, which of these options would motivate students to prepare for class by doing the reading assignments?

A. Daily quizzes over the reading

B. Pop quizzes over the reading

C. Online preparation assignments (as done in this course)

D. Nothing, just assign the reading

E. Class discussion about the reading that assumes the reading was done prior to class

F. Other

Q6. About how much time per week did you spend outside of class working on this course?
A. less than $1 \mathrm{~h} /$ week
B. 1-4 h/week
C. more than $4 \mathrm{~h} /$ week
Q7. Please check all that are true about your learning behavior this semester in this course.
A. I almost always read the book before quizzes.
B. I almost always came to class and was there before class started.
C. I often worked with classmates on the homework.
D. When I got stuck on a problem, I sought help from the textbook
E. When I got stuck on a problem, I visited the professor's office hours.
F. I completed and turned in all homework assignments.
G. I participated in all online quizzes.
H. I made sure I understood the material before each exam.
Q8. Please provide any other comments or suggestions about the quizzes. 